\title{
Peertechz
}

\section{The making and development of Baxter the Empowered Chatbot impered with Machine Intelligence}

Received: 28 May, 2021

Accepted: 11 June, 2021

Published: 12 June, 2021

*Corresponding author: P Girish, JAIN Deemed to Be University, Bangalore, India,

E-mail: GIRISHSTARTUP@GMAIL.COM

Keywords: Artificial intelligence; Machine intelligence; Chatbots; Theory of intelligence machines; Turing tests; Machine learning

https://www.peertechzpublications.com

\section{Check for updates}

\author{
Srimathi Jagadesan ${ }^{1}$, P Girish ${ }^{2 \star}$ and Anugraha Ramesh \\ kurane $^{3}$ \\ ${ }^{1} \mathrm{KGISL}$ Institute of Science and Technology, Coimbatore, India \\ 2JAIN Deemed to Be University, Bangalore, India \\ ${ }^{3} \mathrm{MVJ}$ College of Engineering, Bangalore, India
}

\begin{abstract}
Artificial Intelligence and machine learning in machines is a very challenging discussion. It involves the creation of machines which can stimulate intelligence and adapt to the needs of the human kind. This paper discusses some of the current trends and practices in A.I. and subsequently offers alternative theory for improvement of some of today's prominent postulates. For this, focus on the structuring and functioning of simple - chatbots( or chatter bots) is made. The paper shows how the current approach towards A.I. and M.L. is not adequate and offers a new path that discusses machine learning, machine intelligence, python programming throwing light to the future of Intelligent systems
\end{abstract}

\section{Introduction}

The creation and analysis of intelligent agents (software and machinery) is called Artificial Intelligence. Intelligent machines can do many tasks - from labour work to highly complicated operations. Prominent trends in this field are human brain simulation, natural language processing, neural networking, user friendly operating system, adaptability to ethical and modern engines. One of the typical examples of the A.I. system is a "chatbot". A chatbot is a computer program which responds like an intelligent entity when conversations are discussed. The conversation may be through text, voice, code. Any chatbot program understands human languages by natural language processing. Due to this, the system interprets human beings through input information fed to it. A chatbot also performs some additional functions like calculation, playing songs, calling anyone and small user defined functions. A popular example of the chatbot is BAXTER Bot (Artificial Intelligence combined computer entity) which is a human command execution bot. This chatbot is an innovative interface between human and work engine, making that command flow directly from human to the machine within the input entity (keyboard and microphone etc). The Turing test is one of the most popular measures of intelligence of such machines. The Turing test develops mathematical models of regression. Today's A.I. systems "pretend to act like" intelligent entities instead of being one. For example, today's machines require too much of a heavy dataset but modern A.I. model does not require that much intelligence. There is a need to view AI systems from a new perspective and theory of machine intelligence's required tool for this $[1,2]$.

\section{Functioning of simple A.I. Systems}

Chatbots are one of the most elementary and popular examples of Human Computer Interaction (HCI) for the purpose of ease of operations, we utilise SARANG (in AI and ML) along with BAXTER (integrated user bots). $\mathrm{C}++$, python is a typical general-purpose object oriented programming language for creating applications. Choosing AI-ML gave us the advantage of using open source in research directly, consisting of 50,000 
responses integrated with BAXTER [3-8], it provides a great platform and innovative project which improves the transfer and understanding of messages between human user and AI system. Another section stores the useful key-points and retrieves it later whenever needed. It's arranged in the form of a stack in a library. The program is logically divided into following modules.

\section{Introductory screen}

The welcome screen introduces the user to the program and may ask him some of his/her details like the name, for further conversation purposes. A key point like the user name is good to be stored in a data-file with use of Data Handling.

\section{The chat interface and manager}

This is the main region, where all the text-inputs are managed and the program fetches the best-matching answers from its database. It has to search and display from tens of thousands of rules stored in the database. This is the main region where the text inputs are managed and the program fetches matching answers from the database [10-15]. It's the primary key which stores the data of the user in a unique manner. Along with the data, the accessibility of the chatbot and user friendly review is stored making progress under chatbot.

\section{The Database}

The brain of the chatbot contains an organised, manually created list of suitable replies for questions from the user end. Different varieties and possibilities of questions and combinations of answers is a unique technique utilised by industrial chatbots. The standard of the chatbot depends on continuity and sequential replies provided by the user [16-20].

\section{Productivity application}

The chatbot has been very much better in solving minute tasks like calculations, user appointment, simple program and solving possible equations. Integrated this chatbot with a hardware makes easy utilisation of the hardware component to the full maximum capacity. These days A.I. They have a great platform to offer which includes the virtually intelligent chatbots which take the role of personal assistant in-built in it [20-22].

\section{Ambiguity handling}

Sometimes, the end-user poses questions that a program's database does not have answers to. Here, ambiguity handling comes into play. It gives answers when no relevant data is available. Its contents fit into a wide range of contexts and hence, the user is satisfied even for an unexpected question [22-30].

\section{Data handling}

The user while entering the data automatically, the flow of channels between the instructions which acts as parameter will store the data permanently via data handling. This data are stored for future references and timely circulations of updated information to the user in the form of mail which is looped in circulatory manner [30-32].

\section{Error handling}

The chatbot must be able to tolerate the man made errors and also those errors which are made due to technical issues and newly exchanged data. Thereby making users engage actively providing the responses to the chatbot regulating flow of instructions. The programs should be capable of handling general errors and concentrate on the environment.

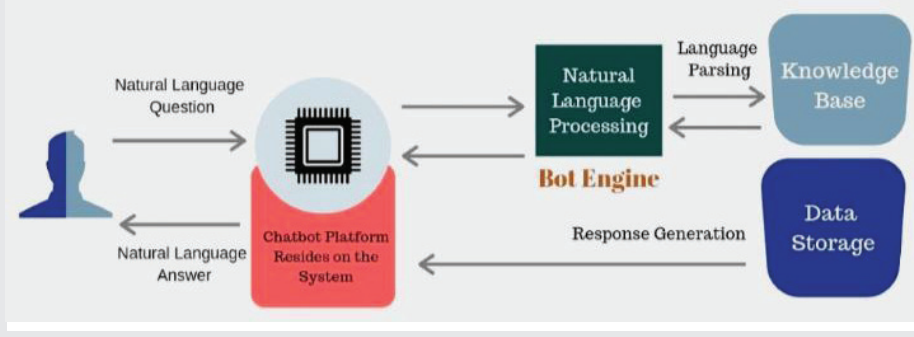

The generational flow of instructions from various parts of a chatbot storing data entry to transfer in a data array index with a perfectly inducted execution of storing,accuring,executing and timely programming of the data and communication of the data to the user helps in efficiently .Also data is acquired and managed by user interfaces and NLP is employed in managing the engine.

of the bots and store data in a highly efficient ai based chatbot development area .Furtherly the chatbot will be managed on the quality check council committee which decides the workflow of the machine particularly in terms of quality.

\section{Design Of paxter chatbot}

The Baxtor chatbot is designed in a way that the user interface is very easy and the data entry mode is very ease possible and user friendly in terms of chatbot provided with a construction of a rapid data storage areas with nlp and network storied regions and user friendly regions.

The chatbot will be enabled with multiple technologies for the same purpose of collection of data from user and efficient storage of the same and timely purpose for execution.

The chatbot has an software and a data managing centre which is managed completely by officials technically 24 hours with a data collecting purpose.

These kinds of chatbots are used in various factors like education,managing,customer data collection and are very easy to collect and maintain with low cost advantage.

\section{Software used in Chatbots}
A)Neural language processing
B)Data structure 
C)Web development

D)Chatbot maker

\section{E)Artificial intelligence}

Example of chatbot paxter used for collecting data in a website for admission purpose

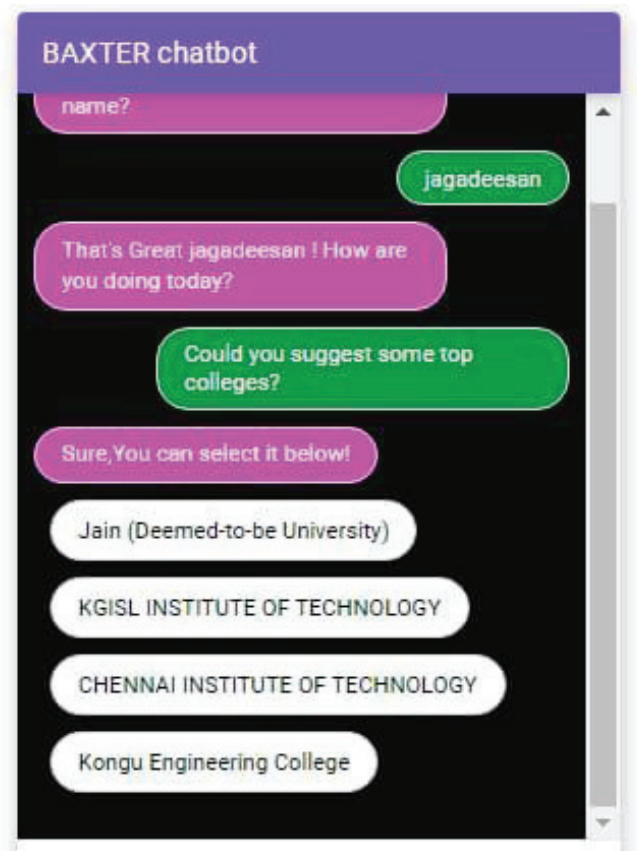

Ask something

The chatbot has been evolved with various methodologies for manufacturing of opinion for the same and display of the institutions using student query map filter which processes instant data continuously using PYTHON,OOPS, structured using JAVA,HTML,HSS along with nlp for the same.

The chatbot involved the great initiative along the construction of a newly implemented models for the same implementation of a low-cost collecting feature for highly secure information oriented system with the customers satisfied UI based interface along with the technological based indexes movement easily e factor chart potholes moment of providing most economical operational experience of a chatbot along with high expertise management and low network running on technology and the greatest initiatives that that packs chatbot to develop the technology that the future technologies villa love just a minute development in the software which will only work with hardware equipments which will afflicted particularly on it with the perfect purpose of collecting data and managing them and storage of them in the stack overflow library which is been assigned to them on the particular basis on the rules of variable regression analyses like the password generation and everything could be stored on a particular basis and along the storage could be maintained easily by HSS format.

The following pic demonstrate the performance of chatbot getting and fixing appointments for a career opportunity on a particular clg on a particular day especially paxtor allows to chat with the academic coordinators of the same with the direct initiative of the chatbot forming a direct mean of communication.

Chatbots like these will provide great flexibility to the academic sector providing the flexibility to the same of educational industry The settings of the industry along with modern components matters a lot in making an economically strong chatbots with data analytics.

\section{We utilized the following tech ideals}

Baxter Chatgen Technologies

Front Stack Development

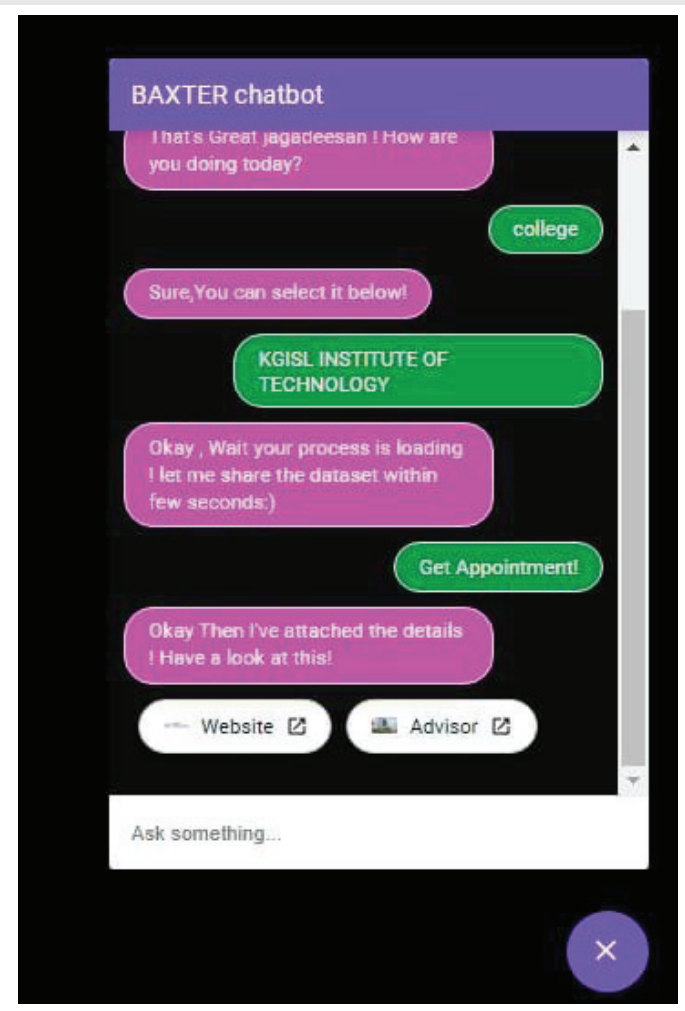

Complete Description Of Student Getting Clarification 2.000

We infer that, using AI-ML with designated application with $\mathrm{AI}$, the total speed of development of the project is boosted along with the efficiency of the program stored. AIML features along with cloud infrastructure are built in a combinational manner with BAXTER which will be able to resolve 60,000 queries and responses fed to it and handle several hundred programs at a single time. BAXTER efficiency is able to component hardware and make it user friendly with any kind of operating system and execute industrial chatbot in a more proficient way. 
The BAXTER chatbot has been equipped with emotional intelligence, workplace knowledge and highly user friendly interface and outstanding shape structure which will make the operation very easy. The factor user interface is in such a way that the user cannot make errors and adaptability to hardware components making itself an adaptive and reactive to the future technologies with a slight change in the in-built structures (Data structures, Data mining, Data science and IOT).

\section{The turing test and its problems}

The Turing test is not a perfect measure to tell if a machine is intelligent. There is perhaps no fool-proof way to tell if an entity is intelligent or not. Sometimes, unintelligent behaviour is witnessed in intelligent beings. On the other hand, dumb machines may at times perform a lot of tasks more intelligently and accurately than intelligent human beings. But the Turing test has its own challenges discussed as follows.

\section{Limitedness}

The test only features intelligence in terms of conversational skills of a machine. Intelligence is a lot more than that.

\section{Short purview}

The scope of this test is only bounded within the limits of human ability to comprehend and respond in a human language. But it is not the only intelligent behaviour seen in the world. What about intelligence in animals? Also, the ability to pass the Turing test is not the only sign of intelligence shown by humans.

\section{Unproductive developments}

Trying to pass the Turing Test is merely a distraction from more fruitful research.

\section{Disillusionment of goals}

Creating lifelike simulations of human beings is a critical task in itself. Such entities may be interesting in a game or maybe as a friendlier user interface, but they are not part of the core science of creating intelligent machines, that is, machines that solve problems using intelligence. The test is not compulsory to be passed for achieving higher goals of AI research

\section{Back to the fundamentals: The meaning of intelligence}

To formulate the postulates, we need some alternatives from scratch and provided that thinking of intelligence depends on following factors.

\section{Arithmetic}

The power to perform basic operation must be computed to the machines and today's machines are capable of performing robust calculations within a fractions of seconds.

\section{Comparison, logic and reasoning}

The scope of machine intelligence becomes wider when a system acquires the ability to apply logic and make comparisons. Today's computers can perform logical operations well with the principles of Boolean algebra.

\section{Learning, heuristics and memory}

Power to recollect past incidents, learn new things and gaining experience constantly are major features of intelligent entities. R\&D is going on in this direction these days. Heuristics is being implemented in newer software and as time passes, the ability of machines to learn and gain experience will grow.

\section{Senses}

Human beings experience sense in the form of emotions and feelings. A machine with properly installed equipment and modules will be able to sense the surroundings and prove to be a greater body to the brain. The machine will be able to react in terms of emergency, disaster management. The machines will be able to stop in case of human error and threaten human life as according to ASIMO rule.

\section{Perception}

This is how we receive and process the signals our senses provide us. This is how creativity is born to intelligence. To have a machine with a perception seems a distant dream of AI.

\section{Consciousness}

Consciousness is one of the most important abilities which humans possess and cannot be defined. A system must be able to recognise its present in the world and perform the program task according to the algorithm. It's evident that, systems have no consciousness

\section{Adaptability}

A machine must be able adapt itself to the modern technology in order to serve long to the future with the purpose. The machine must be user friendly and cannot be robust and flexible with new modules according to the need.

\section{Redefining machine intelligence}

This paper intends to offer an overview regarding BAXTER chatbots integrated with Artificial intelligence along with machine learning.

\section{Statement 1: partially intelligent systems}

Any machine, system or program exhibiting some but not all of the above listed fundamentals of intelligence is a Partially Intelligent System. For example, chatbots exhibit some of the above listed traits, namely Comparison, Logic \& Reasoning and Learning, Heuristics \& Memory. If there is an additional module, they may exhibit some more traits also, like ability to perform arithmetic operations. Therefore, chatbots are Partially Intelligent Systems. Moreover, today's machine intelligence is greatly confined to the boundaries of Partial Intelligence. Even highly capable robots of today are an instance of highly capable Partial Intelligence, as today's AI does not possess complete power of all the fundamentals of intelligence. 


\section{Statement 2: Completely intelligent systems}

Any machine system or program exhibiting all the above mentioned fundamentals would be considered intelligent. Such a machine will stay long and be flexible and adapt to the new modules and standards.

\section{Statement 3: Performance factor}

The Performance Factor of a system is a measure offered for representing the capability of an intelligent system in terms of the fundamental traits of intelligence it possesses. It is given by the number of apparent fundamental traits shown by the given system divided by the number fundamental traits of intelligence, i.e., 6. Its value ranges from 0 to 1 . Hence, today's chatbots showing two or three of the given traits get a Performance Factor score of 0.33 to 0.5. A "Completely Intelligent System" will have a Performance Factor of 1.

\section{Conclusion}

Artificial intelligence is the most important and interesting and challenging field of research today providing employment to most of the data scientists and holding the key role in the economic factor. It also involves the development of products which involves the welfare of humankind and creating employment and converting from a traditional form of manufacturing to a wider newer one. The paper offered an alternate foundation theory of intelligence in machines. The basic work can be carried forward to develop advanced AI theories and systems. Moreover, there is an utter requirement for new theories to emerge and develop, especially in a challenging field like Artificial Intelligence. Artificial intelligence is developing in every field so that the policies and the modules must be made considering the future requirement and flexibility.

\section{Acknowledgements}

We pay sincere acknowledgment to all the authors of all the reference material. Also, the kindest blessings of our parents and all the teachers gave the zeal and faith to put forward this work. Thanks to them.

\section{References}

1. Khanna A, Pandey B, Vashishta K, Kalia K, Pradeepkumar B (2015) A Study of Today's A.I. through Chatbots and Rediscovery of Machine Intelligence. International Journal Service, Science and Technology 8: 277-284. Link https://bit.ly/3pJB1Cu

2. Shawar BA, Atwell E (2007) "Chatbots: are they really useful?". LDV Forum 22 Link: https://bit.ly/3viAfxo

3. Turing AM (1950) "Computing Machinery and Intelligence". Mind 433-460 Link: https://bit.ly/3xiBUoq

4. Khanna A (2015) "Pandorabots Chatbot Hosting Platform. SARANG Bot".

5. Alice Al (2015) "Foundation. Free A.L.I.C.E. AIML Set".

6. Whitby B (2009) Author, "Artificial Intelligence", The Rosen Publishing Group.

7. Weizenbaum J (1966) ELIZA-a computer program for the study of natural language communication between man and machine. Commun ACM 9: 36-45.
Link: https://bit.ly/3ggAy7H

8. Brandtzaeg PB, Følstad A (2017) Why people use chatbots. In: Kompatsiaris I., et al. (eds.) Internet Science, 377-392.

9. Colby KM, Weber S, Hilf FD (1971) Artificial paranoia. Artif Intell 2: 1-25. Link: https://stanford.io/35eNUek

10. Wallace RS (2009) The anatomy of A.L.I.C.E. In: Epstein, R., Roberts, G., Beber G. (eds.) Parsing the Turing Test: Philosophical and Methodological Issues in the Quest for the Thinking Computer. 181-210.

11. Marietto M, Marietto B, Varago de Aguiar R, de Oliveira Barbosa G, Botelho WT, et al. (2013) Artificial intelligence markup language: a brief tutorial. Int J Comput Sci Eng Surv 4 Link: https://bit.ly/3cAX74Y

12. Molnár G, Zoltán S (2018) The role of chatbots in formal education. 2018 IEEE 16th International Symposium on Intelligent Systems and Informatics (SISY). Link: https://bit.ly/3vhQevG

13. Personal Digital Assistant - Cortana Home Assistant - Microsoft. Link: https://bit.ly/2RLDxf0

14. What exactly is Alexa? Where does she come from? And how does she work? Link: https://bit.ly/3veyp03

15. Google Assistant, your own personal Google. Link: https://bit.ly/3iBjsDd

16. IBM Watson. Link: https://ibm.co/3pODOKW

17. Scopus - Document search. Link: https://bit.ly/3iCqFTI

18. Colace F, De Santo M, Lombardi M, Pascale F, Pietrosanto A, et al. (2018) Chatbot for e-learning: a case of study. Int J Mech Eng Robot Res 7: 528-533. Link: https://bit.ly/2TIzHKa

19. Ranoliya BR, Raghuwanshi N, Singh S (2017) Chatbot for university related FAQs. In: 2017 International Conference on Advances in Computing Communications and Informatics (ICACCI). Udupi 1525-1530. Link: https://bit.ly/3zoRDUv

20. da Costa PCF (2018) Conversing with personal digital assistants: on gender and artificial intelligence. J Sci Technol Arts 10: 59-72. Link: https://bit.ly/3gepurF

21. Xu A, Liu Z, Guo Y, Sinha V, Akkiraju R (2017) A new chatbot for custome service on social media. In: Proceedings of the $2017 \mathrm{CHI}$ Conference on Human Factors in Computing Systems. 3506-3510. Link: https://bit.ly/2SsUOtQ

22. Følstad A, Nordheim CB, Bjørkli CA (2018) What makes users trust a chatbot for customer service? An exploratory interview study. In: Bodrunova, S.S. (ed.) INSCI 2018. LNCS, 11193: 194-208. Link: https://bit.ly/3cBCBkD

23. Go E, Sundar SS (2019) Humanizing chatbots: the effects of visual, identity and conversational cues on humanness perceptions. Comput Hum Behav 97: 304-316. Link: https://bit.ly/35rOuaN

24. Sannon S, Stoll B, DiFranzo D, Jung M, Bazarova NN, et al. (2018) How personification and interactivity influence stress-related disclosures to conversational agents. In: Companion of the 2018 ACM Conference on Computer Supported Cooperative Work and Social Computing 285-288. Link: https://bit.ly/3viBxbl

25. Fernandes A (2017) NLP, NLU, NLG and how Chatbots work. Link: https://bit.ly/3vc3B0p

26. Dale R (2016) The return of the chatbots. Nat Lang Eng 22: 811-817. Link: https://bit.ly/3gcJUI0

27. Ramesh K, Ravishankaran S, Joshi A, Chandrasekaran K (2017) A survey of design techniques for conversational agents. In: Kaushik, S., Gupta, D., Kharb, L., Chahal, D. (eds.) ICICCT 2017. CCIS. 750: 336-350. Link: https://bit.ly/3znATNC 
28. Akma N, Hafiz M, Zainal A, Fairuz M, Adnan Z (2018) Review of chatbots design techniques. Int J Comput Appl 181: 7-10. Link: https://bit.ly/3zjrkPz

29. Thomas N (2016) An e-business chatbot using AIML and LSA. Link: https://bit.ly/3guc7T7

30. Artificial Intelligence Scripting Language - RiveScript.com. Link: https://www.rivescript.com/
31. Jung S (2019) Semantic vector learning for natural language understanding Comput Speech Lang 56: 130-145. Link: https://bit.ly/3xgDmrf

32. Canonico M, Russis LD (2018) A comparison and critique of natural language understanding tools. Link: https://bit.ly/3vhwQPt
Discover a bigger Impact and Visibility of your article publication with

\section{Peertechz Publications}

\section{Highlights}

* Signatory publisher of ORCID

* Signatory Publisher of DORA (San Francisco Declaration on Research Assessment)

* Articles archived in worlds' renowned service providers such as Portico, CNKI, AGRIS, TDNet, Base (Bielefeld University Library), CrossRef, Scilit, J-Gate etc.

* Journals indexed in ICMJE, SHERPA/ROMEO, Google Scholar etc.

* OAl-PMH (Open Archives Initiative Protocol for Metadata Harvesting)

* Dedicated Editorial Board for every journal

* Accurate and rapid peer-review process

* Increased citations of published articles through promotions

* Reduced timeline for article publication

Submit your articles and experience a new surge in publication services (https://www.peertechz.com/submission).

Peertechz journals wishes everlasting success in your every endeavours.

Copyright: @ 2021 Jagadesan S, et al. This is an open-access article distributed under the terms of the Creative Commons Attribution License, which permits unrestricted use, distribution, and reproduction in any medium, provided the original author and source are credited.

Citation: Jagadesan S, Girish P, Kurane AR (2021) The making and development of Baxter the Empowered Chatbot impered with Machine Intelligence. Trends Comput Sci Inf Technol 6(2): 036-041. DOI: https://dx.doi.org/10.17352/tcsit.000037 